\title{
BASIC PROBLEMS WITH THE USE OF RESILIENT DENTURE LINING MATERIALS: LITERATURE REVIEW
}

\author{
Mariana Yankova ${ }^{1}$, Todor Peev ${ }^{2}$, Bozhidar Yordanov ${ }^{1}$, \\ 1) Department of Prosthetic Dental Medicine, Faculty of Dental Medicine, \\ Medical University - Sofia, Bulgaria. \\ 2) Private Practice, Sofia, Bulgaria.
}

\begin{abstract}
SUMMARY
Complicated cases in the treatment of totally edentulous patients, as well as in the fabrication of obturators and epitheses, require the use of resilient lining materials (RLMs). These materials have several disadvantages, which is why many dental practitioners do not recommend them. The tendency to breaking the bond between the hard acrylic resin and the resilient liner is a fact with unpleasant consequences, mainly found with the use of cold-curing siliconebased resilient liners. Methods to improve the bond between the hard denture base and the RLM have been the subject of numerous publications. The efforts of the authors are focused in two directions: mechanical or chemical treatment of the denture base or a combination of both. Other commonly discussed problems with the use of RLMs are the difficult and even impossible repair and the retention of oral fluids, fungi and other microorganisms due to the porosity of RLMs. Despite the wide variety of tools offered by different manufacturers, the issue of optimal and high-quality mechanical treatment of the polymerized resilient material has not yet been fully resolved.
\end{abstract}

Keywords: resilient denture lining materials, twolayer denture, basic problems, bond, fracture

\section{INTRODUCTION:}

The main disadvantages of resilient lining materials (RLMs) are well systematized by Grant, Heath and McCord [1] and Basker, Davenport and Thomason [2]. They are the reason for many dentists not to recommend them. Even Grant et al. [1] consider that the denture should first be made of conventional hard acrylic resin and, if there is a strict indication of resilient lining, that it be placed in the second stage. The tendency to the breaking of the bond between the hard acrylic resin and the resilient liner is a fact with unpleasant consequences, mainly found with the use of cold-curing silicone-based resilient liners. Other commonly discussed problems with the use of RLMs are the difficult and even impossible repair [1] and the reten- tion of oral fluids, fungi and other microorganisms due to the porosity of RLMs. Materials with higher final hardness (Shore A) are more compact and harder to retain microorganisms [3, 4]. Despite the wide variety of tools offered by different manufacturers, the issue of optimal and high-quality mechanical treatment of the polymerized resilient material has not yet been fully resolved. Poor post-polymerization treatment of the lining material can result in the breaking of the bond with the base.

\section{OBJECTIVE}

The objective of this review is to present and analyze up-to-date literature on the main and most common problems related to removable denture lining with resilient materials.

\section{MATERIALS AND METHODS}

From January 2019 to January 2020, an electronic search was conducted in the PubMed, Google, EBSCOhost and Science Direct databases. The following keywords were used: "resilient/soft denture lining materials", "twolayer denture", "types of denture lining materials", "Unterfütterung", "Unterfütterungskunststoff", "bond to the denture base", "basic problems", "denture fracture". The final selection included 49 publications, the data of which were analyzed, summarized and presented in the main body of this review.

\section{RESULTS}

The question of the durability of resilient materials has been discussed in the literature [5] and considered depending on their composition. Unlike silicone-based denture liners, acrylic-based resilient liners quickly deteriorate their properties. They tend to absorb water and change their composition [2]. Resilient liners should be replaced every 9-18 months [1]. Wright [4] has reported 9-year successful results in prosthetics of 22 patients with the heat-curing silicone-based material Molloplast B (Detax, GmbH \& Co, KG, Germany), Fig. 1. 
Fig. 1. Lower denture, lined with a silicone-based resilient material (authors' clinical case)

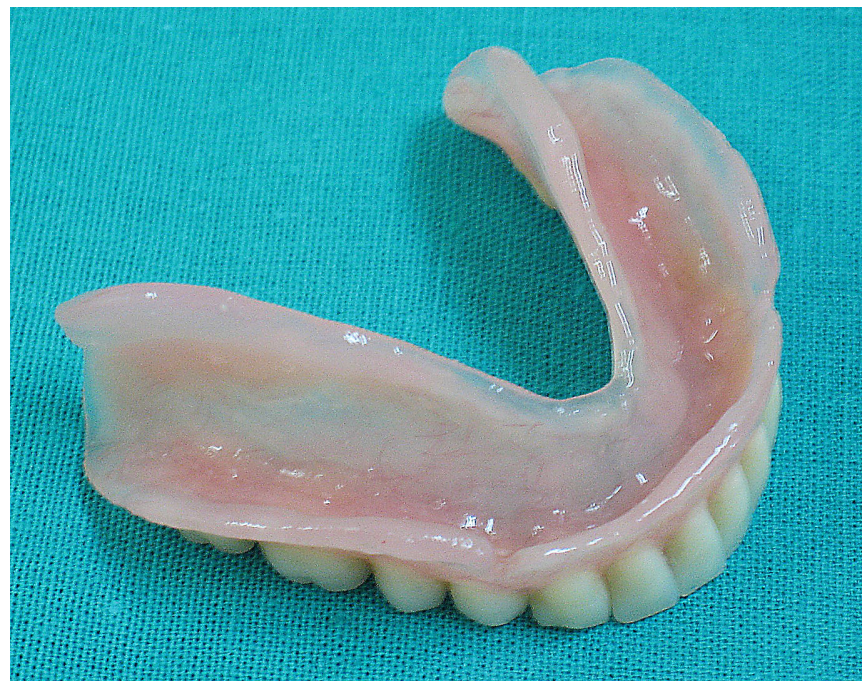

Recent studies have indicated that the retention of microorganisms is the result of insufficient cleaning. According to Basker, Davenport and Thomason [2], a diet with fewer carbohydrates would reduce the supply of nutrients to the microorganisms, Fig. 2. According to the authors, cleaning with sodium hypochlorite is most effective, although it may lead to discoloration and corrosion of the metal elements (if any).

Fig. 2. Colonization of Candida albicans on lower dentures, lined with a silicone-based resilient material after 6 months of use (authors' clinical cases)

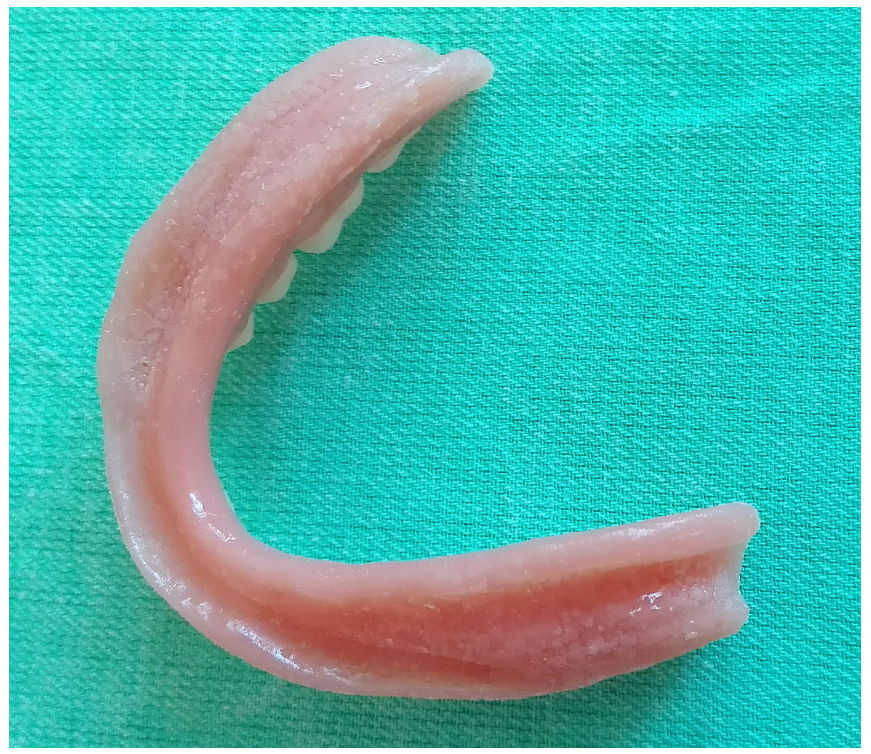

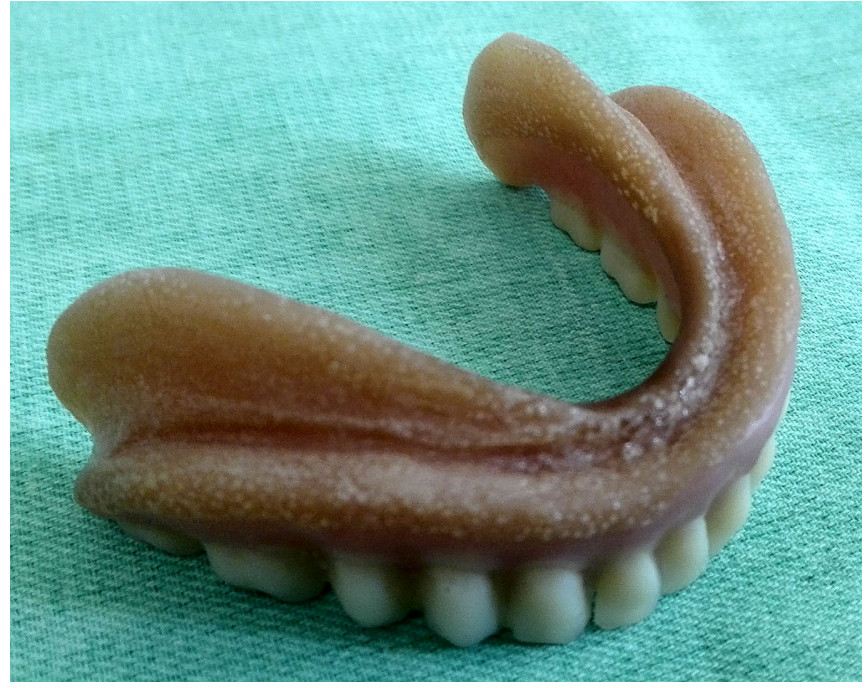

According to Grant et al. [1], the thickness of the resilient liner should be at least $3.0 \mathrm{~mm}$, and, according to Basker, Davenport and Thomason [2], a thickness greater than $2.0 \mathrm{~mm}$ is not needed. In 2013, Lima et al. [5] also found that the stress in the underlying mucosa is the lowest when the thickness of the lining material is not more than $2.0 \mathrm{~mm}$. The greater thickness of the liner reduces the thickness of the base of hard acrylic resin, which may lead to its fracturing, Fig. 3.

Fig. 3. Fractures of dentures lined with a siliconebased resilient material (authors' clinical cases)
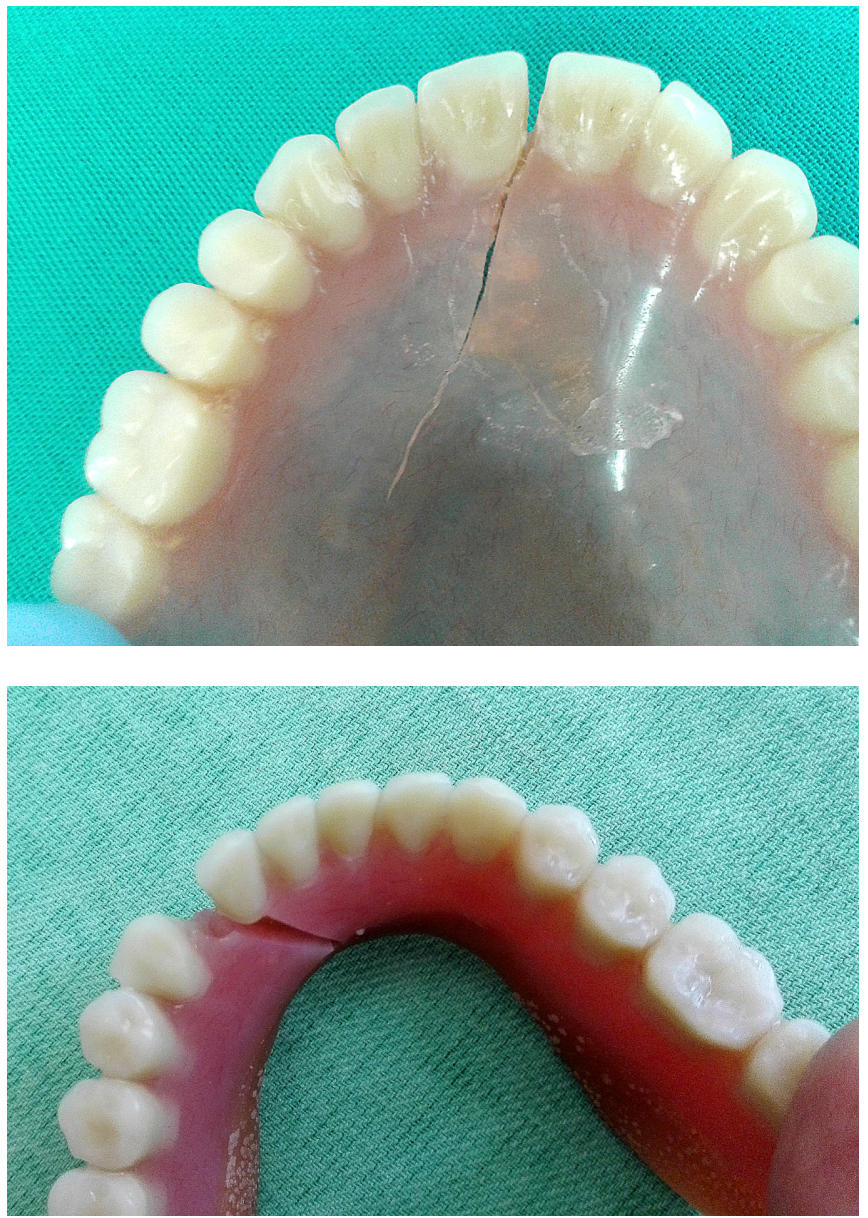
Methods for strengthening the base are provided in the literature. Basker, Davenport and Thomason [2] and others [6] propose the inclusion of a metal plate. A number of other authors [7 - 10] recommend the use of fiberglass. Vergani et al. [11] and other authors [12] have reported the effect of post-polymerization microwave radiation on the flexural strength of Lucitone 550 hard heat-curing acrylic resin, which may increase the durability of the dentures.

Another major problem is the bond between the hard acrylic resin and the RLM.

\section{Bond characteristics}

The bond between the hard acrylic resin and the RLM can be of two types: mechanical and chemical, depending on the chemical composition of the materials. Acrylic-based RLMs chemically bond with the acrylic resin of the denture. In the case of silicone-based lining materials, the bond is predominantly micromechanical, and additional means - adhesives or polymeric solvents (primers), are used to improve it, Fig. 4a, b.

Fig. 4a. Adhesive bonding of A-Silikon to PMMA (Göbel 2001, cited by Otto 2004, [13])

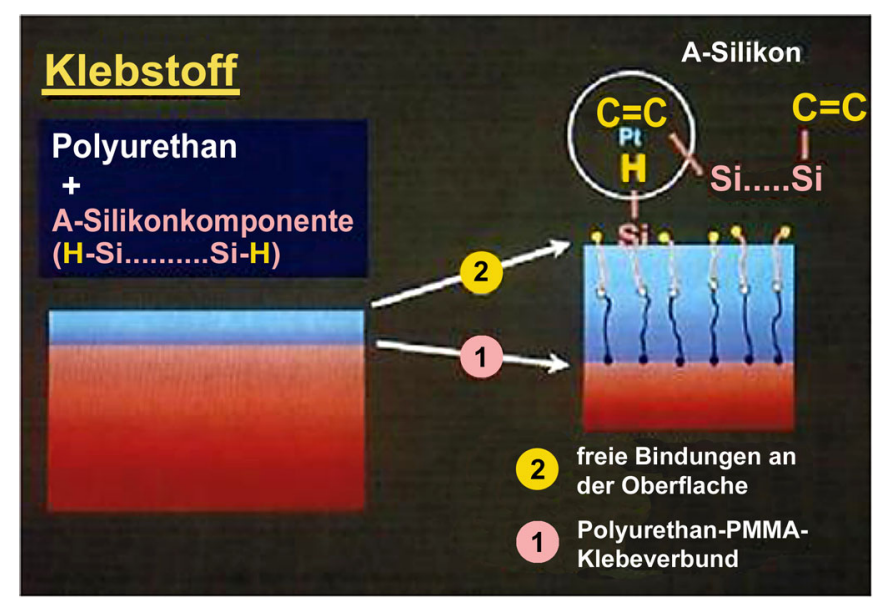

Fig. 4b. Primer bonding of À-Silikon to PMMA (Göbel 2001, cited by Otto 2004, [13])

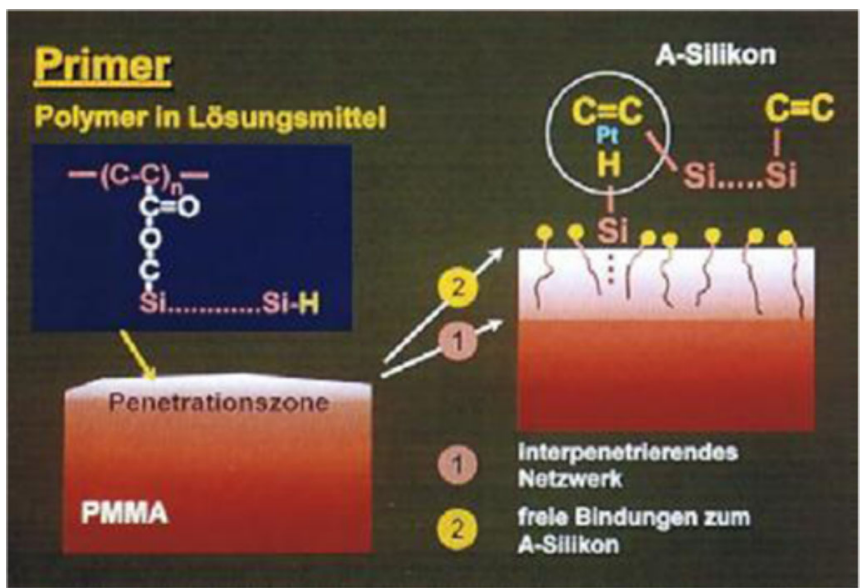

When bonded by a polyurethane adhesive containing an A-silicone reactive component, a bond resistant to the tensile strength of $200 \mathrm{~N} / \mathrm{cm}^{2}$ is formed [13]. Adhesives contain a polymeric substance in a solvent. The polymeric substance may be a reactive molecule (organosilane) or a molecule such as PMMA in a solvent. The use of adhesive is appropriate for the indirect technique since the drying time is prolonged. In the direct technique, primers are more commonly used. The solvent contained in the primer dissolves the plastic surface and introduces the adhesive bonding polymer. After evaporation of the solvent, the hydrocarbon chains of the in the primer bind to the polymer of the matrix. The formed network in the superficial dissolved layer is a mechanical-chemical bond. On the other hand, the polymer contains reactive $\mathrm{Si}-\mathrm{H}$ and vinyl groups that are ready for chemical bonding with the A-silicone. The primer technology is affordable, easy to implement, held for a short time, and provides tensile strength and shear strength of $190-220 \mathrm{~N} / \mathrm{cm}^{2}$ [13]. The most commonly used primers are: ethyl acetate, dichloromethane, a mixture of methoxy and ethoxy silanes, methylene chloride, etc. The durability of the bond depends on the mechanical stresses, the coefficient of thermal expansion, the modulus of elasticity of the various materials, the solubility and the imbibition [14].

Bond breaking can occur at the border between the different materials, and then it is defined as adhesive. If the cause of the bond breaking is a tear of the resilient material, it is defined as cohesive, Fig. 5 and 6.

Fig. 5. Cohesive and adhesive types of bond breaking (D. Otto 2004 [13])

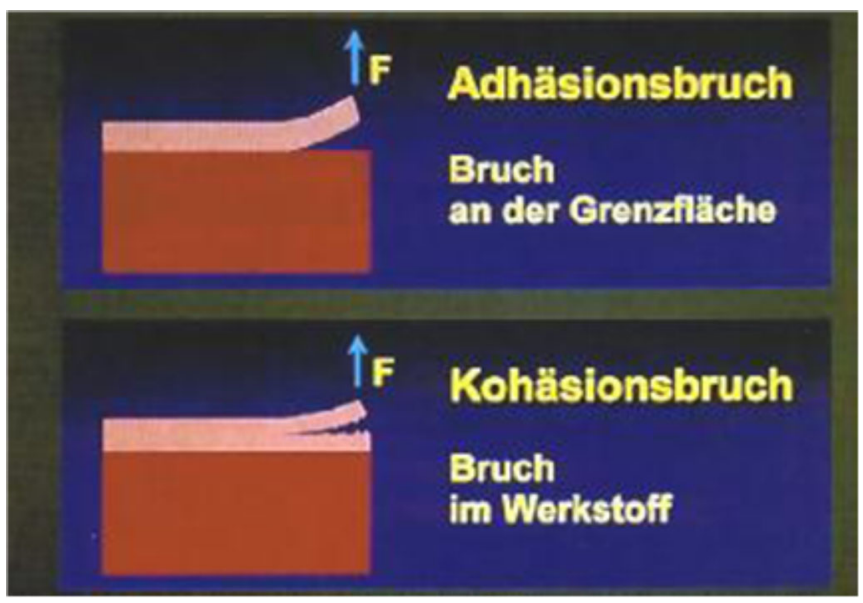


Fig. 6. Adhesive type of bond breaking (authors' clinical cases)
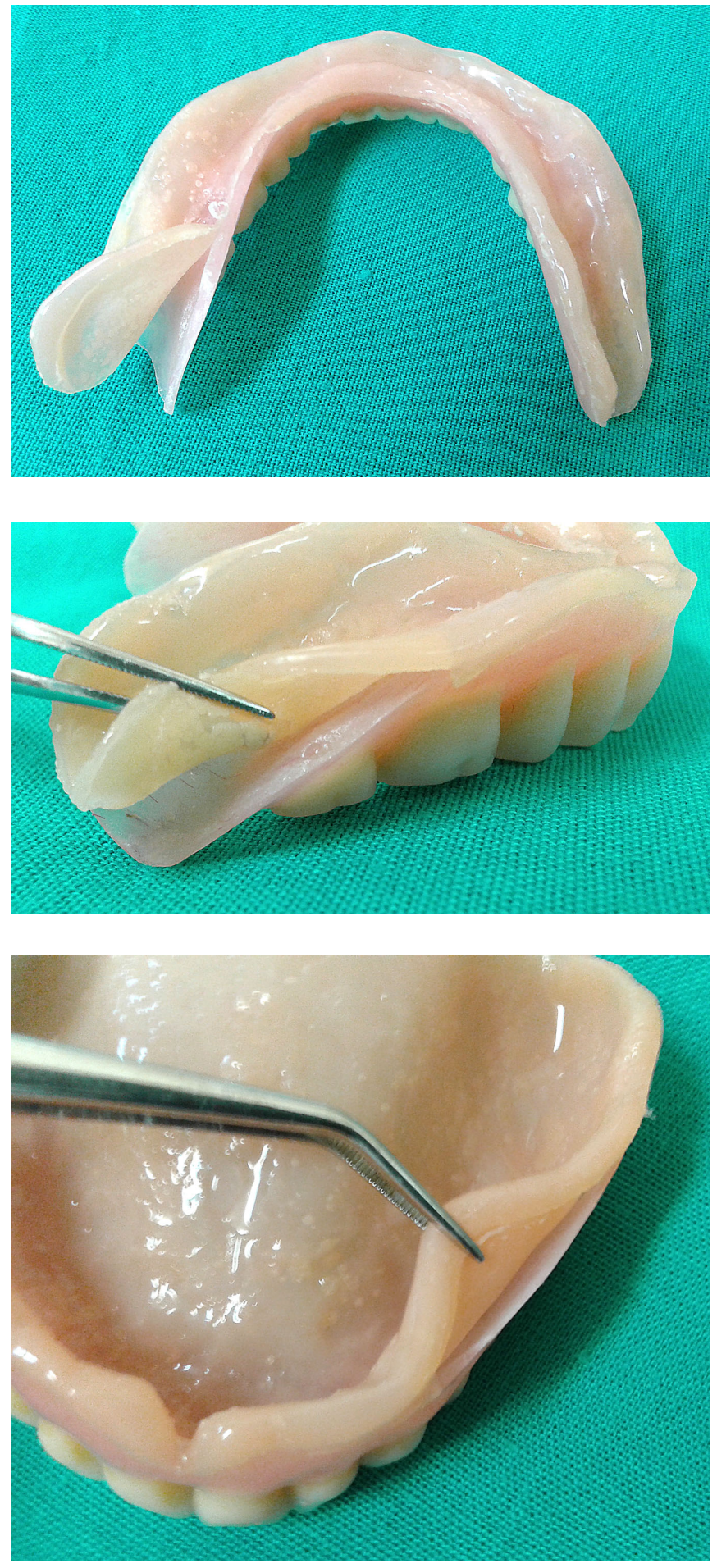

The minimum binding strength acceptable for clinical use is $0.44 \mathrm{MPa}$ [15 - 17]. Popular methods of evaluating the bond strength are tests for tensile strength, shear strength [14] and peel bond strength [17 - 20]. The peel bond strength is a test to measure the strength of the bond between two materials. Although tensile strength tests do not simulate clinically common forces, the method is considered indicative.

Wiêckiewicz et al. [21] investigated the adhesion strength by comparing tensile strength and shear strength.
The bond strength was acceptable for all studied materials. For Elite Soft Relining, a tensile strength of $1.00 \mathrm{MPa}$ and lower shear strength of $0.67 \mathrm{Mpa}$ were found, as opposed to Dentusil (tensile strength of $0.86 \mathrm{MPa}$ and shear strength of 1.57 Mpa) and A-Soft Line 30 (tensile strength of 1.25 MPa and shear strength of $1.32 \mathrm{Mpa}$ ). Differences in values may be the cause of a different type of bond breaking (adhesive, cohesive or mixed) [22].

Lau et al. [23] compared different materials and found that RLMs had lower tensile and shear strength values than hard acrylic resins. Contradictory are the results regarding the dependence of the thickness of the lining layer - strength and type of bonding. According to Muralidhar, Satish and Shetty [24], the thickness of the layer is irrelevant, while AlAthel and Jagger [25] share a completely opposite view. The type of polymerization influences the adhesion strength of the RLM to PMMA. Cold-curing silicones, cross-linked by heat, show higher shear strength: Ufi Gel P (with heat - 2.39 $\mathrm{MPa}$, without heat - $1.74 \mathrm{Mpa}$ ) and SilagimComfort (with heat - 3.09 MPa, without heat - 2.21 Mpa) [26].

\section{Bond improving methods}

The improvement of the bond between the hard denture base and the RLM has been the subject of numerous publications. The efforts of the authors are focused in two directions: mechanical or chemical treatment of the denture base or a combination of both. In 2012, Philip, Ganapathy and Ariga [27] examined the tensile strength (after preliminary mechanical and chemical treatment) between a polyvinylsiloxane soft liner and an acrylic denture base and concluded that pretreatment with a sandblasting apparatus and a monomer significantly increased its value. They obtained the following results for the different treatments: acetone treatment $-0.043 \mathrm{MPa}$, monomer treatment - 0.054 $\mathrm{MPa}$, surface sandblasting - $0.0615 \mathrm{MPa}$, jet-abrasive treatment - $0.0727 \mathrm{MPa}$, sandpaper treatment and a monomer $0.082 \mathrm{MPa}$ and jet-abrasive treatment plus a monomer 0,111 MPa. After being stored in water, all values increased.

In the same year, Kazanji and Abid Al-Kadder [28] investigating Molloplast B (heat-curing silicone), GS Reline (cold-curing silicone), and Bony plus (cold-curing acrylicbased material), offered a 032-bur treatment to increase bond strength. Tensile strength was increased more for Molloplast B than for GS Reline and Bony plus. Arafa [29] also has reported that treatment with a monomer increases bond strength. According to him and other authors [30], treatment with a laser weakens the bond, and treatment with $\mathrm{Al}_{2} \mathrm{O}_{3}$ sand strengthens it. On the other hand, a number of other publications do not recommend jet-abrasive treatment, but only one with a monomer [31 - 33]. Atsü [34], after testing several types of treatment (adhesive, sandblasting, silica coating, and combination) with Ufi Gel P, found that the strongest bond was when using an adhesive alone (1.35 MPa). The values for the jet-abrasive treatment and the silica coating were $0.28 \mathrm{MPa}$ and $0.34 \mathrm{Mpa}$, respectively. The low bond strength can be explained by the stresses occurring in the border band and the reduced ability of the material to penetrate the PMMA irregularities. This was confirmed by other authors [35 - 37]. Korkmaz et al. [19] applied several conditioning methods: 
1. jet-abrasive treatment $(50 \mu \mathrm{m})$

2. Er-Cr: YSGG laser (Waterlase MD Turbo, Biolase Technology) with different parameters: $2 \mathrm{~W}, 20 \mathrm{~Hz} ; 2 \mathrm{~W}, 30$ $\mathrm{Hz} ; 3 \mathrm{~W}, 20 \mathrm{~Hz}$ and $3 \mathrm{~W} / 30 \mathrm{~Hz}$. When measuring the peel bond strength, they found that treatment with a $3 \mathrm{~W}, 20 \mathrm{~Hz}$ laser is most effective. The values obtained after treatment were in the range of $3.9 \mathrm{MPa}-5.58 \mathrm{Mpa}$, with values for the control group of $3.64 \mathrm{MPa}-4.58 \mathrm{MPa}$. The values for the jet-abrasive treatment were much lower $(3.1 \mathrm{MPa}-4.46$ $\mathrm{MPa}$ ), and it was not recommended, especially for polyamide resins (Deflex). Akin et al. [38] confirmed the conclusion of Korkmaz et al. [19]. They treated acrylic denture bases with sandblasting and various lasers (Er: YAG, Nd: YAG and KTP lasers) and reported that treatment with an Er: YAG laser increases the bonding strength and sandblasting and Nd: YAG and KTP lasers reduce it. Tugut et al. [39] found that long pulse length Er: YAG $(300 \mathrm{~mJ}, 3 \mathrm{~W})$ causes significant changes in texture and improves adhesion between the denture base and the resilient liner.

Gupta [15], after treating the denture base surface with acetone for 30 seconds, the monomer for 180 seconds and methylene for 15 seconds, has found that the flexural strength of the acrylic resin decreases. The flexural strength values were determined after simulating accelerated aging by thermal cycling $\left(500\right.$ cycles at $\left.5^{\circ} \mathrm{C}-55^{\circ} \mathrm{C}\right)$ and 30 minutestorage in water. For the control untreated base surfaces, the flexural strength values were $781.19 \mathrm{~kg} / \mathrm{cm}^{2}$, when treated with monomer for 180 seconds $-725.09 \mathrm{~kg} / \mathrm{cm}^{2}$, when treated with methylene chloride and acetone, $715.78 \mathrm{~kg} / \mathrm{cm}^{2}$ and $711.81 \mathrm{~kg} / \mathrm{cm}^{2}$, respectively. Demir et al. [40] studied the effect of different reactive surface agents on the tensile strength between the RLMs and the denture base. Maleic anhydride (MA) is a reactive monomer that contains an unsaturated double bond and acid anhydride groups that allow chemical bonding with the resin. Treatment with $2 \% \mathrm{MA}$ in butanone, added to the primer prior to adhesive application, has shown the highest tensile strength values of $2.53 \mathrm{Mpa}$, and the lowest values were obtained with $20 \%$ MA. Hatamleh et al. [8] have reported increased bond strength of Molloplast B to a fiber-reinforced StickTech acrylic base. According to Lassila et al. [9], denture base reinforcement with fiberglass should be carefully considered. Increasing bond strength is not valid for all materials. According to the authors, the bond strength of the cold-curing silicones studied by them is determined by the binding agent. Only the Softreliner Tough with the ethyl acetate primer was registered to increase the bond strength. For a primer polymer in 2-butanone (Ufi Gel SC) and polyacryl in dichloromethane (Vertex SoftSil 25), the bond strength even decreases, as with the Eversoft acrylic-based resin material. In 2017, Hristov [41] suggested a method for improving the bonding by using retentive pearls in the hard resin/resilient material border zone.

Studies in recent years have confirmed that the bond strength between acrylic resilient lining materials and polymethyl methacrylate denture base is of the highest quality. Bonding to acrylic plastic for CAD-CAM - IvoBase CAD is the weakest and the strongest when the resilient material is applied to non-polymerized polymethyl methacrylic resin.
The latter is only possible with acrylic-based resilient materials and with Molloplast B - a resilient silicone-based heatcuring material. A number of authors have confirmed that pretreatment of the denture base with oxygen plasma, monomer, acetone or isobutyl methacrylate (iBMA) leads to improved bond strength with the resilient material and thermocycling and sandblasting - to its deterioration [42].

\section{Treatment of RLMs}

After compression in the laboratory or functional molding in the patient's mouth, there is always a surplus of resilient material that has to be removed. Initially, this is done with a sharp scalpel. This is followed by machining with various cutting tools [13]. Despite the wide variety of tools offered by different manufacturers, the issue of optimal and high-quality machining of polymerized resilient material is not fully resolved. It is necessary to distinguish between shape correction and smoothing. In the resilient material/hard resin border zone, materials with clearly different properties come in contact. The roughness of the materials is undesirable because it creates conditions for bacterial retention and the development of fungal infections. All these features greatly increase the requirements for the treating tools. The various RLM manufacturers offer their own cutting tools in the commercial kits, Fig. 7 [13].

The special milling cutters of Komet, Germany are GSQ or FSQ. When working with them, low pressure and speed of 15,000-30,000 r/min are used. For Mucopren soft ${ }^{\circledR}$ products of Kettenbach, Germany and Elite ${ }^{\circledR}$ soft relining of Zhermack, Italy, double-cut hard alloy cutters are available.

Fig. 7. Tools for treating RLMs (D. Otto 2004 [13]) A. Grinding cap 180 ìm granularity (NTI- Kahla, Germany), B. Grinding cap 150 ìm granularity (NTI-Kahla, Germany), C. Rough polishing silicone H332 (DIT Diamant, Germany), D. Fine polishing silicone H332f (DIT Diamant, Germany), E. FSQ H79FSQ.104.070 Fräse (Komet, Germany), F. GSQ H79GSQ.104.070 Fräse (Komet, Germany), G. Hard alloy cutter (KETTENBACH, Germany), H. Lisco - rough (Erkodent, Germany), I. Lisco - fine (Erkodent, Germany), J. Soft Wizard ${ }^{\circledR}$ (NTI- Kahla, Germany);

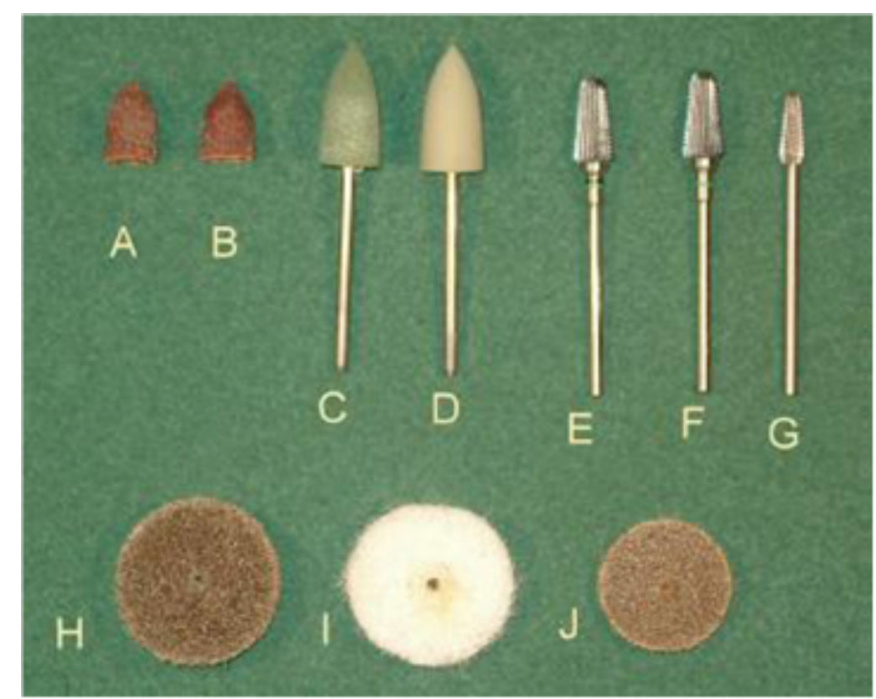


The elastic material UfiGel C® of Voco, Germany is treated with non-woven abrasive discs with various sizes of the abrasive particles under the name Lisko (Erkodent, Germany). The discs are designed for pre-polishing and are of four types - rough, medium, fine and super fine. In the first three varieties, the abrasive particles are coated with synthetic resin and in the finest - with latex. For its products, Molloplast B®, Mollosil® and Mollosil plus ${ }^{\circledR}$, Detax, Germany offers a toolkit containing cutters, caps with different abrasive properties (abrasive particle size of $150 \mu \mathrm{m}$ and $180 \mu \mathrm{m}$ ) and pre-polishing discs, Fig. 8.

The instrument Soft Wizard ${ }^{\circledR}$ of NTI-Êahla, Germany, is a soft, elastic wheel with an optimum size of the abrasive particles, Fig. 9.

Fig. 8. A kit of polishing instruments (Detax, Germany)

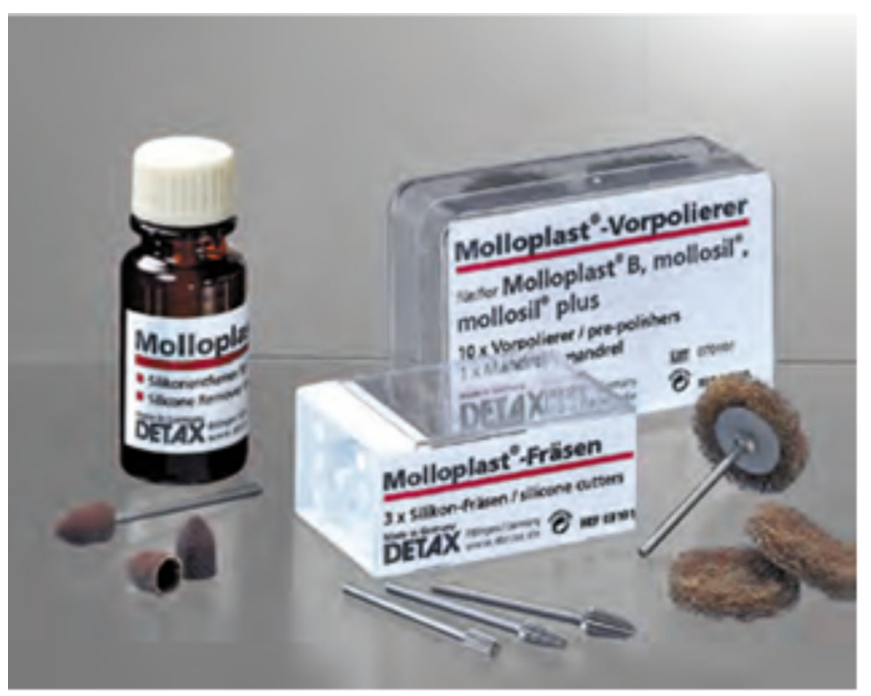

Fig. 9. Soft Wizard ${ }^{\circledR}$ (NTI-Kahla, Germany)

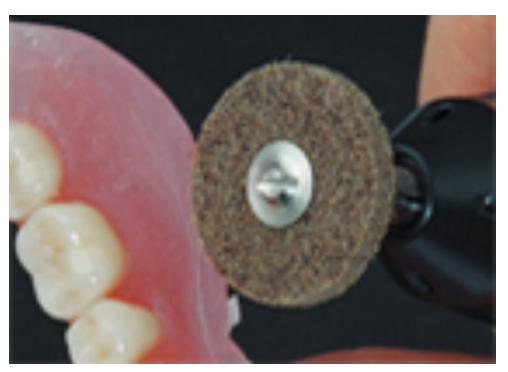

Pesun, Hodges and Lai [43] examined the surfaces of RLMs after treatment and have reported that all tools adequately reduce the resilient liner volume. According to the authors, machining with diamond files leaves many scratches and should be followed by machining with carbide finishing burs or carbide milling cutters. The authors compared the surfaces of polished and unpolished material and noted that the final polishing with pumice and tin oxide paste gives the best results. The pumice erases scratches on the surface and provides a smooth surface for tin oxide polishing. It is confirmed that Molloplast $B$ (Detax, GmbH \& Co, KG, Germany) should be treated with stones of different abrasive properties prior to polishing. Immersion of soft liner dentures in ice water facilitates their treatment. Silicone-based RLMs are difficult to polish. To optimize their surface treatment, different varnishes for surface sealing are available on the market for dental products. These are incompletely filled, low-viscosity A silicones that cannot chemically bind to the base material due to the lack of free binding sites in the polymerized silicone. The lacquer coating remains as a film on the silicone, which is peeled off after a few months and needs new application.

\section{CONCLUSION}

Despite the efforts of many authors to find a solution to improve the compromised stability of the full dentures [44-47] and the bond between the denture base and the resilient lining material in the case of cold-curing silicone-based resilient liners, this problem is still unsolved and remains a matter of scientific interest.

\section{REFERENCES:}

1. Grant AA, Heath JR, McCord JF. Complete prosthodontics - problems, diagnosis and management. Wolfe. 1994: 123-125.

2. Basker RM, Davenport JC. Thomason JM. Prosthetic Treatment of the Edentulous Patient. Blackwell Publishing Company, Fifth edition. 2011: 214-218, 224-226, 228-244.

3. Wright PS, Young KA, Riggs PD, Parker S, Kalachandra S. Evaluating the effect of soft lining materials on the growth of yeast. J Prosthetic Dentistry. 1998 Apr;79(4):404-9. [PubMed]
4. Wright PS. Observations on longterm use of a soft-lining material for mandibular complete dentures. $J$ Prosthet Dent. 1994 Oct;72(4):385-92. [PubMed]

5. Lima JBG, Orsi IA, Borie E, Lima JH, Noritomi PY. Analysis of stress on mucosa and basal bone underlying complete dentures with different reliner material thicknesses: a three-dimensional finite element study. J Oral Rehabil. 2013 Oct;40(10):767-73. [PubMed]

6. Balch JH, Smith PD, Marin MA,
Cagna DR. Reinforcement of a mandibular complete denture with internal metal framework. J Prosthet Dent. 2013 Mar;109(3):202-5. [PubMed]

7. Hatamleh MM, Maryan CJ, Silikas N, Watts DC. Effect of Net Fiber Reinforcement Surface Treatment on Soft Denture Liner Retention and Longevity. J Prosthodont. 2010 Jun;19(4): 258-62. [PubMed]

8. Lassila LV, Mutluay MM, Tezvergil-Mutluay A, Vallittu PK. Bond strength of soft liners to fiber-reinforced denture-base resin. J Prostho- 
dont. 2010 Dec;19(8):620-4. [PubMed]

9. Narva KK, Lassila LV, Vallittu PK.

The static strength and modulus of fiber reinforced denture base polymer. Dent Mater. 2005 May;21(5):421-8. [PubMed]

10. Vallittu PK. A Review of FiberReinforced Denture Base Resins. J Prosthodont. 1996 Dec;5(4):270-6. [PubMed]

11. Vergani CE, Seo RS, Pavarina AC, dos Santos Nunes Reis JM. Flexural strength of autopolymerizing denture reline resins with microwave post-polymerization treatment. $J$ Prosthet Dent. 2005 Jun;93(6):577-83. [PubMed]

12. Machado AL, Giampaolo ET, Pavarina AC, Jorge JH, Vergani CE . Surface roughness of denture base and reline materials after disinfection by immersion in chlorhexidine or microwave irradiation. Gerodontology. 2012 Jun;29(2):e375-82. [PubMed]

13. Otto D. [Klinische und experimentelle Untersuchungen weichbleibender und harter Unterfütterungskunststoffe] [dissertation]. [in German], Medizinischen Fakultät der FriedrichSchiller-Universität Jena. 2004. [nternet]

14. Anastasov I. [Dental material science.] [in Bulgariàn] Sofia Smile Center Publishing House, Sofia. 2013:159-161.

15. Gupta S. Effect of Surface Treatment on the Flexural Strength of Denture Base Resin and Tensile Strength of Autopolymerizing Silicone Based Denture Liner Bonded to Denture Base Resin: An In Vitro Study. J Indian Prosthodont Soc. 2010 Dec;10(4):20812. [PubMed]

16. Kulak-Ozkan Y, Sertgoz A, Gedik H. Effect of thermocycling on tensile bond strength of six silicone-based, resilient denture liners. J Prosthetic Dent. 2003 Mar;89(3):303-10. [PubMed]

17. Maeda T, Hong G, Sadamori S, Hamada T, Akagawa Y. Durability of peel bond of resilient denture liners to acrylic denture base resin. J Prosthodont Res. 2012 Apr;56(2):136-41. [PubMed]

18. Demir H, Dogan A, Dogan OM, Keskin S, Bolayir G, Soygun K. Peel Bond Strength of Two Silicone Soft Liners to a Heat-cured Denture Base Resin. J Adhes Dent. 2011;13(6):579-

\section{4. [PubMed]}

19. Korkmaz FM, Bagis B, Ozcan M, Durkan R, Turgut S, Ates SM. Peel strength of denture liner to PMMA and polyamide: laser versus air-abrasion. $J$ Adv Prosthodont. 2013 Aug;5(3):287295. [PubMed]

20. Sertgöz A, Kulak Y, Gedik H, Taskonak B. The effect of thermocycling on peel strength of six soft lining materials. J Oral Rehabil. 2002 Jun;29(6):583-7. [PubMed]

21. Wieckiewicz W, Kasperski J, Wieckiewicz M, Miernik M, Król W. The adhesion of modern soft relining materials to acrylic dentures. Adv Clin Exp Med. 2014 Jul-Aug;23(4):621-5. [PubMed]

22. Marcotte H, Lavoie MC. Oral microbial ecology and the role of salivary immunoglobulin A. Microbiol Mol Biol Rev. 1998 Mar;62(1):71-109. [PubMed]

23. Lau M, Amarnath GS, Muddugangadhar BC, Swetha MU, Das KA. Tensile and shear bond strength of hard and soft denture relining materials to the conventional heat cured acrylic denture base resin: An In-vitro study. $J$ Int Oral Health. 2014 Apr;6(2):55-61. [PubMed]

24. Muralidhar G, Satish Babu CL, Shetty S. Integrity of the interface between denture base and soft liner:A scanning electron microscopic study. $J$ Indian Prosthodont Soc. 2012 Jun; 12(2):72-7. [PubMed]

25. Al-Athel MS, Jagger RG. Effect of test method on the bond strength of a silicone resilient denture lining material. J Prosthet Dent. 1996 Nov;76(5): 535-40. [PubMed]

26. Zhang F, Shi L, Deng L, Zhang L, Zeng Y, Tu T. [Effect of different polymerization methods on shear bond strength between polymethyl methacrylate and silicone soft liner]. [in Chinese] Hua Xi Kou Qiang Yi Xue Za Zhi. 2014 Jun;32(3):292-6. [PubMed]

27. Pajukoski H, Meurman JH, Snellman-Grohn S, Keinanen S, Sulkava R. Salivary flow and composition in elderly patients referred to an acute care geriatric ward. Oral Surg Oral Med Oral Pathol Oral Radiol Endod. 1997 Sep;84(3):265-271. [PubMed]

28. Kazanji MN, Abid Al-Kadder AA. Evaluation of the bond strength of three soft lining materials to acrylic resin denture base. Al-Rafidain Dent J. 2012; 12(1):57-65.

29. Arafa KAO. Effect of Soft Liner Material on Retention of Complete Denture, (An In Vitro Study) Life Sci J. 2012; 9(2):1296-99. [Crossref]

30. Jacobsen NL, Mitchell DL, Johnson DL, Holt RA. Lased and sandblasted denture base surface preparations affecting resilient liner bonding. J Prosthet Dent. 1997 Aug;78(2):1538.. [PubMed]

31. Kulkarni RS, Parkhedkar R. The effect of denture base surface pretreatments on bond strengths of two long term resilient liners. J Adv Prosthodont. 2011 Mar;3(1):16-9. [PubMed]

32. Surapaneni H, Ariga $P$, Haribabu R, Ravi Shankar Y, Kumar VHC, Attili $\mathrm{S}$. Comparative evaluation of tensile bond strength between silicon Soft liners and processed denture base resin conditioned by three modes of surface treatment: An in vitro study. J Indian Prosthodont Soc. 2013 Sep;13(3):27480. [PubMed]

33. Vallittu PK, Lassila VP, Lappalainen R. Wetting the repair surface with methyl methacrylate affects the transverse strength of repaired heatpolymerized resin. J Prosthet Dent. 1994 Dec;72(6):639-43. [PubMed]

34. Atsü S, Keskin Y. Effect of silica coating and silane surface treatment on the bond strength of soft denture liner to denture base material. J Appl Oral Sci. 2013 Jul-Aug;21(4):300-6. [PubMed]

35. Hristov I, Pavlov B, Ivanova D, Georgieva I. A comparative study on the bonding strength between the denture base and the relining marerials. J of IMAB. 2006; 12(2):2829. [Internet]

36. Minami H, Suzuki S, Ohashi H, Kurashige H, Tanaka T. Effect of surface treatment on the bonding of an autopolymerizing soft denture liner to a denture base resin. Int J Prosthodont. 2004 May-Jun;17(3):297-301. [PubMed]

37. Aras MA, Nagarsekar A. Evaluation of the effect of denture base surface treatment on tensile bond strength of RTV silicone soft denture liners. $J$ Indian Dent Assoc. 2013; 7(1):20-25.

38. Akin H, Tugut F, Mutaf B, Akin G, Ozdemir AK. Effect of different sur- 
face treatments on tensile bond strength of silicone-based soft denture liner. Lasers Med Sci. 2011 Nov;26(6):7838. [PubMed]

39. Tugut F, Akin H, Mutaf B, Akin GE, Ozdemir AK. Strength of the bond between a silicone lining material and denture resin after Er:YAG laser treatments with different pulse durations and levels of energy. Lasers Med Sci. 2012 Mar;27(2):281-5. [PubMed]

40. Demir H, Soygun K, Dogan A, Keskin S, Dogan OM, Bolayir G. Effect of Maleic Anhydride Pretreatment on Tensile Bond Strength of a Silicone Soft Liner to a Denture Base Polymer. $J$ Adhes Dent. 2011 Oct;13(5):481-7. [PubMed]
41. Hristov Il. [Up-to-date analysis of soft rebasing materials and ways to address their shortcomings.] [disertation] MU-Plovdiv. 2017. pp.106-116. [in Bulgarian]

42. Khanna A, Bhatnagar VM, Karani JT, Madria K, Mistry S. A Comparative Evaluation of Shear Bond Strength Between Two Commercially Available Heat Cured Resilient Liners and Denture Base Resin with Different Surface Treatments. J Clin Diagn Res. 2015 May;9(5):ZC30-4. [PubMed]

43. Pesun IJ, Hodges J, Lai JH. Effect of finishing and polishing procedures on the gap width between a denture base resin and two long-term, resilient denture liners. J Prosthet Dent. 2002 Mar;87(3):311-8. [PubMed]
44. Hadjieva H, Dimova M, Todorov S. Stomatitis prosthetica - A polyetiologic disorder. J of IMAB. 2006; 12(2):38-41. [Internet]

45. Dimova M, Hadjieva H. Total prosthetics in function. J of IMAB. 2006; 12(2):42-44. [Internet]

46. Hadjieva H, Dimova M, Krasteva A, Petrov T. Clinical Case of Allergic Contact Occupational Dermatitis Caused by Methyl methacrylate Monomer. J of IMAB. 2006; 12(2):3537. [Internet]

47. Hadjieva H, Dimova M. Selective Pressure Impression Methods for Total Dentures by Patients with Loose and Hypermobile Mucosa on the Alveolar Ridges. J of IMAB. 2005; 11(2):51-53. [Internet]

Please cite this article as: Yankova M, Peev T, Yordanov B. Basic Problems with the Use of Resilient Denture Lining Materials: Literature Review. J of IMAB. 2021 Apr-Jun;27(2):3723-3730.

DOI: https://doi.org/10.5272/jimab.2021272.3723

Received: 14/05/2020; Published online: 11/05/2021

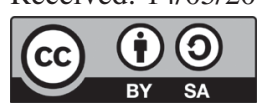

\author{
Address for correspondence: \\ Dr Mariana Yankova, PhD \\ cal University - Sofia, \\ 1, St. G. Sofiiski Blvd., Sofia, Bulgaria \\ e-mail: marianayankova13@gmail.com
}

Department of Prosthetic Dental Medicine, Faculty of Dental Medicine, Medi- 